\title{
VARIATION IN THE SIZE OF ABDOMINAL AORTA MEASURED ON COMPUTED TOMOGRAPHY
}

\author{
DOLLY SHARMA ${ }^{1 *}$, VISAKH T
}

${ }^{1}$ Department of Medical Imaging Technology, Charotar Institute of Paramedical Sciences, Charusat University, Changa, Gujarat, India. 2Department of Medical Imaging Technology, SOAHS, Manipal University, Manipal, Karnaka, India. Email: sdolly468@gmail.com

Received: 25 May 2018, Revised and Accepted: 02 July 2018

ABSTRACT

Objective: The normal size of the abdominal aorta is expected to be $<3 \mathrm{~cm}$ though the size changes with age as well as workload. There is a need to know the variation in size of the abdominal aorta to avoid the formation of aneurysm and further complications.

Materials and Methods: This study was carried out at Kasturba Medical College after taking 130 patients considering the inclusion and exclusion criteria. 130 patients who all came for abdomen computed tomography (CT) were divided into 65 patients in each age group under 20-40 years and 40-80 years. The measurements of abdominal aorta were anteroposterior (AP) and right left (RL) measured at T12-L1 level on plain axial abdomen CT images on Extended Brilliance Workstation.

Result: We observed that there was a statistical significant difference in the average AP diameter between the two age groups ( $<<0.001)$. Another finding was a statistical significant difference in the average RL diameter between the two age groups ( $<<0.001)$, and, hence the size of abdominal aorta varies with age.

Conclusion: The proposed study concluded that there was variation in the size of abdominal aorta with age. These findings would be helpful in early detecting of aneurysm and in avoiding aortic dissection.

Keywords: Aortic dissection, Ectasia, Extended brilliance workstation, Multidetector computed tomography.

(C) 2018 The Authors. Published by Innovare Academic Sciences Pvt Ltd. This is an open access article under the CC BY license (http://creativecommons. org/licenses/by/4. 0/) DOI: http://dx.doi.org/10.22159/ajpcr.2018.v11i11.27553

\section{INTRODUCTION}

Arteries are complex organ because of their bifurcation and subdivisions at different levels in the body. The normal diameter of abdominal aorta is expected to be $<3.0 \mathrm{~cm}$, but with time the size of the aorta varies. [1]. The normal change rate in size is about $1-2 \mathrm{~mm} /$ year. Variation in size can be observed in childhood as well as in adulthood due to exercise and workload [2]. If the increase in diameter of abdominal aorta exceeds $50 \%$, this results in the presence of ectasia which further turns into the formation of aneurysm [3]. Aneurysm is defined as dilatation of abdominal aorta. Abdominal aorta aneurysms are not harmful as long as there are no complications because symptoms are not produced by enlargement in diameter alone unless overexpansion occurs. Aortic dissection and rupture can also be seen in abdominal aorta due to aortic diameter and expansion rate [4]. The probability of aneurysm occurrence is low during the first two decades of life and increases usually after the third decade [5]. The rate of aneurysm rupture increases with age [6]. The expansion rate for abdominal aorta is $2.6 \mathrm{~mm}$ /year. The diameter increases as the aneurysm enlarges [7]. There are various imaging modalities available to screen or to detect the early abnormal changes in size of abdominal aorta such as ultrasonography (USG), computed tomography (CT), angiography, and magnetic resonance imaging (MRI). Ultrasound is always a first choice of screening arteries because it is simple, inexpensive and involves no exposure of radiation to patients [4]. The studies earlier have used ultrasound because of its practical and economic reasons [8]. In the present study, CT is used for screening of early changes in size of abdominal aorta. CT has become an important pre-operative imaging technique well as less operator dependent and more objective [4,9]. CT has various tools and techniques to measure the size of arteries [10-12], while in the present study, 2D axial sections were taken to measure the variation in size of the abdominal aorta.

\section{MATERIALS AND METHODS}

An evaluative study was conducted using purposive sampling technique for 3 months after obtaining the institutional and hospital ethical clearance from Kasturba Medical College. Patients who all were referred for abdomen CT were included in the study. The age ranged between 20 and 80 years. Patients with abdominal trauma, operation, and metallic implants were excluded from the study. Sample size was calculated using paired t-test. Total patients were 130 , and 65 patients per gender group who all met inclusion criteria were involved in the study.

Abdomen CT was performed on MDCT Brilliance 64 slice Philips with a scan time of $0.4 \mathrm{~s}$ at an interval of $5 \mathrm{~mm}$ from $\mathrm{C} 6$ to the diaphragm using a collimation of $64 \times 0.65$ and slice thickness of $5 \mathrm{~mm}$ with abdomen filter to get better images.

During the scan, patients were instructed to breathe at full inspiration and hold his/her breathe for $1 \mathrm{~s}$ during scanning to reduce motion artifacts.

The original series of abdomen CT was taken with a slice thickness of $5 \mathrm{~mm}$ and incrementation of $5 \mathrm{~mm}$ with a standardized window and width $(60 / 360)$ settings for the abdomen and sent to a dedicated extended brilliance workstation, and using common measuring tool size of abdominal aorta is measured at the level of T12-L1 in axial planes. Collected data were analyzed using SPSS 16 software (Fig. 1)

\section{RESULTS}

We performed independent sample t-test to know the significant difference in the average anteroposterior (AP) and right-left (RL) diameters between the two age groups.

Mean and standard deviation (SD) of aortal measurements for the two age categories are provided in Table 1.

We observed that there was a statistical significant difference in the average AP and RL diameters of two age groups $(\mathrm{p}<0.001)$.

\section{DISCUSSION}

There are various modalities available to measure the diameters of vessels such as CT, USG, and MRI; however, in the present study, anteroposterior 


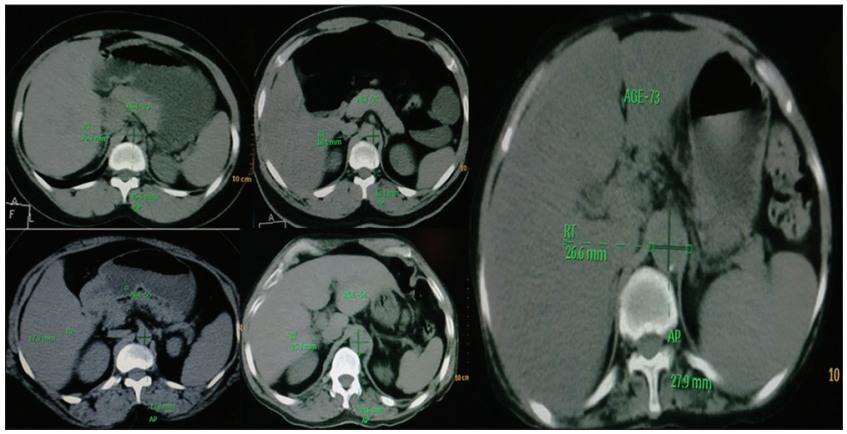

Fig. 1: Axial images of abdomen computed tomography showing an increase in size of abdominal aorta with age

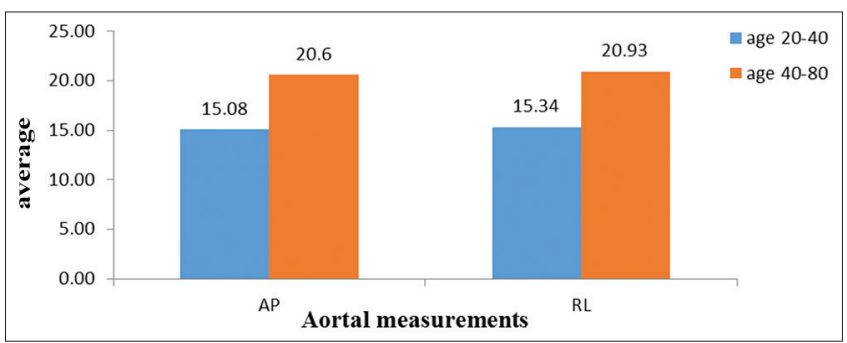

Fig. 2: Histogram shows the variation in anteroposterior and right left measurement of abdominal aorta with the age group of 20-40 years and $40-80$ years

Table 1: Mean and SD of AP and RL diameters for the two age categories

\begin{tabular}{lll}
\hline Aortal measurements & Age group & Mean $\pm($ SD) \\
\hline $\mathrm{AP}$ & $20-40$ & $15.08 \pm 1.42$ \\
& $40-80$ & $20.60 \pm 2.47$ \\
$\mathrm{RL}$ & $20-40$ & $15.34 \pm 1.35$ \\
& $40-80$ & $20.93 \pm 2.68$ \\
\hline
\end{tabular}

SD: Standard deviation, AP: Anteroposterior, RL: Right left

(AP) and transverse diameters (RL) were measured on non-contrast axial plane of abdomen CT images because measurements made on images CT are less likely to be affected by gastrointestinal gas or any other body parts [4]. Our study shown that there is a significant variation in size of the aorta with age that means as age increases, there is a change in the diameters of aorta also. Similar findings were reported in the study performed by Sariosmanoglu et al. in year 2002 reflecting a significant correlation of aortic diameter with age [13]. Länne et al. measured the changes in the diameter of the distal abdominal aorta in 76 healthy Caucasian males aged 5-71 years old using an ultrasound phase-locked echo-tracking system and concluded that the diameter of the abdominal aorta increases with age and the increase was about $30 \%$ between the ages of 25 and 71 years, and this change may be due to the pressure strain and stiffness of the aorta increased in an ex-potential manner with age. Both these pressure strain and stiffness were seen more in the aneurysm group than in the control group, pointing toward the possible involvement of pressure strain and stiffness in the pathogenesis of abdominal aortic aneurysm [14]. In this study, we have divided our patients into two age groups 20-40 years and 40-80 years, AP and RL diameters were measured at the level of T12-L1 on axial images of abdomen CT, (Fig. 1) we found a mean difference of 15.08 with standard deviation of 1.42 in 20-40, mean difference of 20.60 with standard deviation of 2.7 in 40-80 age group for AP diameter, a mean difference of 15.34 with standard deviation of 1.35 in $20-40$, and mean difference of 20.93 with standard deviation of 2.68 in 40-80 years of age group as shown in Fig. 2. We investigated that there was statistical significant difference in the average AP and RL diameters of the two age groups $(p<0.001)$. There are existed studies performed using computed tomography and ultrasound to screen abdominal aorta for mortality benefits of human and to avoid the formation of aneurysm $[15,16]$. Lederle et al. [17] analyzed the variation in aortic diameters measured using both CT and USG in 258 patients and observed a difference of $<0.2 \mathrm{~cm}$ in $44 \%$ and at least $0.5 \mathrm{~cm}$ in $33 \%$ in CT, and US-based measurements were smaller than the CT-based measurements by an average of $0.27 \mathrm{~cm}$, but Wanhainen et al.[9] observed that US-based measurements were larger by $2.8 \mathrm{~mm}$ than CT-based measurements. In the present study, we have observed the same findings, and the variability of measurements between US and CT depends on the diameter of the aorta and how it is measured. There is no gold standard to measure the variation in size of the abdominal aorta [4], so the measurements of abdominal aorta made on CT images in this study were not enough to get a positive result. We could not get the correlation of variation in size of the abdominal aorta with gender since it was timebound study and sample size was not enough to make a strong conclusion.

\section{CONCLUSION}

Our study concluded that there was significant variation in size of the abdominal aorta with age. Further studies can be performed using variables such as gender and habits into consideration.

\section{ACKNOWLEDGMENT}

We are thankful to the Department of Radiodiagnosis at Kasturba Medical College, Manipal, for their approval and permission in collecting the data and carrying out this study smoothly. We also acknowledge the Department of Statistics, Manipal, for their guidance during data analysis and interpretation.

\section{AUTHORS' CONTRIBUTION}

This study was designed by Dolly Sharma and data required to complete this study were collected by Visakh T. The manuscript is written by Dolly Sharma.

\section{CONFLICTS OF INTEREST}

The authors have no conflict of interest related to this paper.

\section{REFERENCES}

1. Erbel R, Eggebrecht H. Aortic dimensions and the risk of dissection. Heart 2006;92:137-42.

2. Devereux RB, de Simone G, Arnett DK, Best LG, Boerwinkle E, Howard BV, et al. Normal limits in relation to age, body size and gender of two-dimensional echocardiographic aortic root dimensions in persons $\geq 15$ years of age. Am J Cardiol 2012;110:1189-94.

3. Hager A, Kaemmerer H, Rapp-Bernhardt U, Blücher S, Rapp K, Bernhardt TM, et al. Diameters of the thoracic aorta throughout life as measured with helical computed tomography. J Thorac Cardiovasc Surg 2002;123:1060-6.

4. Joh JH, Ahn HJ, Park HC. Reference diameters of the abdominal aorta and iliac arteries in the korean population. Yonsei Med J 2013;54:48-54.

5. Niryana W, Pagehgiri AW, Widyadharma PK. Mircosurgical clippning in the ruptured an aneurysm of anterior communicating artery: A case report. Asian J Pharm Clin Res 2017;10:7-9.

6. Johansson G, Markström U, Swedenborg J. Ruptured thoracic aortic aneurysms: A study of incidence and mortality rates. J Vasc Surg 1995;21:985-8.

7. Agmon Y, Khandheria BK, Meissner I, Schwartz GL, Sicks JD, Fought AJ, et al. Is aortic dilatation an atherosclerosis-related process? Clinical, laboratory, and transesophageal echocardiographic correlates of thoracic aortic dimensions in the population with implications for thoracic aortic aneurysm formation. J Am Coll Cardiol 2003;42:1076-83.

8. Bengtsson $\mathrm{H}$, Bergqvist $\mathrm{D}$, Jendteg $\mathrm{S}$, Lindgren $\mathrm{B}$, Persson $\mathrm{U}$. Ultrasonographic screening for abdominal aortic aneurysm: Analysis of surgical decisions for cost-effectiveness. World J Surg 1989;13:266-71.

9. Wanhainen A, Bergqvist D, Björck M. Measuring the abdominal aorta with ultrasonography and computed tomography-difference and variability. Eur J Vasc Endovasc Surg 2002;24:428-34.

10. England A, Niker A, Redmond C. Variability of vascular CT measurement techniques used in the assessment abdominal aortic aneurysms. Radiography 2010;16:173-81. 
11. Diehm N, Kickuth R, Gahl B, Do DD, Schmidli J, Rattunde H, et al. Intraobserver and interobserver variability of 64-row computed tomography abdominal aortic aneurysm neck measurements. J Vasc Surg 2007;45:263-8.

12. Diehm N, Baumgartner I, Silvestro A, Herrmann P, Triller J, Schmidli J, et al. Automated software supported versus manual aorto-iliac diameter measurements in CT angiography of patients with abdominal aortic aneurysms: Assessment of inter- and intraobserver variation. Vasa 2005;34:255-61

13. Sariosmanoglu N, Ugurlu B, Karacelik M, Tuzun E, Yorulmaz I, Manisali M, et al. A multicentre study of abdominal aorta diameters in a turkish population. J Int Med Res 2002;30:1-8.

14. Länne T, Sonesson B, Bergqvist D, Bengtsson H, Gustafsson D.
Diameter and compliance in the male human abdominal aorta: Influence of age and aortic aneurysm. Eur J Vasc Surg 1992;6:178-84.

15. Thompson SG, Ashton HA, Gao L, Scott RA. Multicentre aneurysm screening study group. Screening men for abdominal aortic aneurysm: 10 year mortality and cost effectiveness results from the randomized multicentre aneurysm screening study. Br Med J 2009;338:230-7.

16. Cosford PA, Leng GC. Screening for abdominal aortic aneurysm. Cochrane Database Syst Rev 2007;2:CD002945.

17. Lederle FA, Wilson SE, Johnson GR, Reinke DB, Littooy FN, Acher CW, et al. Variability in measurement of abdominal aortic aneurysms. Abdominal aortic aneurysm detection and management veterans administration cooperative study group. J Vasc Surg $1995 ; 21: 945-52$ 